HEINIG, Paul-Joachim, JAHNS, Sigrid, SCHMIDT, Hans-Joachim, SCHWINGES, Rainer Christoph, WEFERS, Sabine, Reich, Regionen und Europa in Mittelalter und Neuzeit. Festschrift für Peter Moraw

Joseph Morsel

\title{
OpenEdition
}

Journals

Édition électronique

URL : http://journals.openedition.org/ifha/1259

DOI : 10.4000/ifha.1259

ISSN : 2198-8943

Éditeur

IFRA - Institut franco-allemand (sciences historiques et sociales)

Référence électronique

Joseph Morsel, «HEINIG, Paul-Joachim, JAHNS, Sigrid, SCHMIDT, Hans-Joachim, SCHWINGES,

Rainer Christoph, WEFERS, Sabine, Reich, Regionen und Europa in Mittelalter und Neuzeit. Festschrift für

Peter Moraw », Revue de l'IFHA [En ligne], Date de recension, mis en ligne le 01 janvier 2001, consulté le 22 septembre 2020. URL : http://journals.openedition.org/ifha/1259 ; DOI : https://doi.org/10.4000/

ifha. 1259

Ce document a été généré automatiquement le 22 septembre 2020.

(CIFHA 


\section{HEINIG, Paul-Joachim, JAHNS, Sigrid, SCHMIDT, Hans-Joachim, SCHWINGES, Rainer Christoph, WEFERS, Sabine, Reich, Regionen und Europa in Mittelalter und Neuzeit. Festschrift für Peter Moraw}

Joseph Morsel

1 Peter Moraw, né en 1935 et professeur depuis de nombreuses années à l'université de Gießen, est l'un des historiens allemands les plus connus outre-Rhin et ailleurs, notamment de tous ceux qui travaillent sur la fin du Moyen Âge. Ses domaines de prédilection sont la Landesgeschichte, l'histoire des universités et surtout l'histoire politique et institutionnelle de l'Empire, qu'il a renouvelée en y introduisant la démarche prosopographique et surtout en rejetant comme parfaitement anachronique la notion moderne d'« État » pour la compréhension de l'Empire à la fin du Moyen Âge, jusqu'alors réduit à une situation de crise et de décadence. Outre leur contenu, l'une des particularités qui identifient les travaux de P.M. est le langage de celui-ci, volontiers abstrait et précis, qui a donné naissance à des notions qui sont depuis devenues courantes chez les historiens allemands (königsfern, königsnah, gestaltete Verdichtung, etc.) et qui réservent des maux de tête aux traducteurs. Comme il est d'usage général outre-Rhin, cet historien a bénéficié de volumes d'hommage pour ses 60 ème et 65 ème anniversaires (en attendant 2005...).

2 Le premier est un recueil de douze articles de P.M. de 1975 à 1993 traitant spécifiquement de l'histoire de l'Empire et de la royauté à la fin du Moyen Âge. Trois textes sont d'ordre méthodologique : un appel à l'usage de la prosopographie pour l'étude des institutions royales et deux bilans historiographiques (en 1977 et en 1993) sur l'histoire institutionnelle. Viennent ensuite des travaux qui concernent plus 
particulièrement les rapports entre le pouvoir royal et les pouvoirs locaux : les " courroies de transmission » du pouvoir qu'est l'« administration », les concurrents que sont les princes et leur organisation territoriale, les alliés que sont censées être les villes libres et impériales, qui apparaissent comme les grandes porteuses de l'idée impériale à défaut de soutenir nécessairement les rois ou empereurs mêmes. Certains moyens de mise en forme de l'idée impériale sont ensuite rappelés : les collégiales (royales mais pas seulement), l'historiographie et la « langue politique ", le Reichstag. Le volume s'achève sur trois réflexions sur les modalités et les fondements de l'évolution de l'Empire : l'articulation entre eux des Stände (" états ») composant l'Empire, l'idée de l'Empire, l'Occident médiéval (examen comparé de l'évolution allemande et occidentale durant tout le Moyen Âge). Un index vient coiffer l'ensemble et permettre ainsi une circulation interne au sein de ces diverses contributions ; l'intérêt de cet index ne se limite pas à cela : outre les noms et choses médiévales (comme tout index nominum et rerum), on y trouve également des notions historiographiques (königsfern, Verdichtung, etc.) et méthodologiques (Modell, Geschichtsbild, Anachronismus, Begriffsanalyse, etc.) ainsi que les noms d'historiens (Below, Bosl, Brunner, Fawtier, etc.), qui permettent ainsi de tenter de reconstruire le paysage historiographique et théorique dans lequel se meut P.M.

3 Cinq ans après, le volume d'hommage est cette fois un volume de mélanges offerts par une quarantaine d'historiens à P.M. et abordant non seulement les thèmes évoqués précédemment, mais aussi certains qui avaient été laissés de côté, notamment l'histoire des universités. Dans la mesure où il ne saurait être question d'analyser ici chacune des quelque quarante contributions $\mathrm{du}$ volume, on se contentera d'en signaler la thématique. Cinq sections composent le volume. La première est consacrée au thème " morawien " par excellence, l'ordre politique impérial médiéval, conçu principalement sous l'angle des représentations et théories du pouvoir. Y sont évoqués la royauté miraculeuse du haut Moyen Âge et du Moyen Âge central, les conceptions du pouvoir de Frédéric II, le problème du consensus politique, l'élection royale à la fin du Moyen Âge et à l'époque moderne, la révolte cabochienne, l'introduction de la valeur de liberté dans les principes politiques à l'époque moderne et contemporaine, enfin l'évolution historique du droit des gens. La deuxième section est tournée vers les mises en pratique et traductions institutionnelles des théories et représentations politiques : l'émission de diplômes impériaux (notamment destinés aux " étrangers ») des Ottoniens aux Staufen, les relations entre Venceslas et Giangaleazzo Visconti, la religion civique dans l'Italie du XVe s., les liens financiers entre la papauté et le Nord de l'Europe à la fin du Moyen Âge, la hiérarchie des justices aux Pays-Bas, la diète de Ratisbonne de Noël 1471, la diète de Worms de 1495, l'éventuelle tentative d'approche de l'Occident par Ivan le Terrible, enfin un conflit en Mecklembourg à l'époque moderne entre des conceptions régionalistes et centralistes. La troisième section entend rendre compte du souci de P.M. pour l'approche prosopographique, donc l'étude des groupes à travers les personnes. Sont étudiés de façon collective les princes assassinés au Moyen Âge, l'activité des premiers Franciscains en Allemagne, les nobles prussiens et livoniens en Europe occidentale au XVe s., le parc hôtelier à Rome en 1468-1469, les relations et les carrières de petits aristocrates palatins au XVe s., la carrière politique du démocrate libéral Carl Vogt, enfin les Allemands, Polonais et Juifs de Haute-Silésie au XIXe s. La quatrième section traite de l'université et de l'enseignement. On y trouvera traités l'autorité morale de l'université de Paris auprès des princes européens du Moyen Âge (seule contribution en français, due à J. VERGER), des aspects particuliers concernant 
des universités ou hautes écoles à Lubeck et à Cologne à la fin du Moyen Âge, en HesseDarmstadt et Hesse-Cassel, à Gießen et à Marbourg à l'époque moderne, et des considérations plus générales sur l'Université dite " classique » (du XIXe s.) et sur l'historiographie des facultés de médecine de la fin du XIXe à la fin du XXe s. La cinquième et dernière section est réservée à l'historiographie, médiévale (la manière dont les médiévaux ont traité du passé, celui de l'abbaye de Reichenau vu par un participant au concile de Constance, celui de l'Empire et des princes de Bavière selon l'historiographe Ulrich Füetrer) ou moderne : le problème du Sonderweg allemand (ici contesté et rejeté pour cause d'anachronisme), le caractère récent et artificiel des spécialisations académiques examiné à travers le cas d'une carrière professorale du XIXe s., l'image du Moyen Âge en Allemagne avant et après 1945, enfin le succès du « symbolique » dans la médiévistique contemporaine (depuis les années 1970, à la suite des ancêtres M. Bloch et P.E. Schramm). 